African Journal of Educational Studies in Mathematics and Sciences Vol. 7, 2009

\title{
Looking at gender disparity in science and mathematics from other angles: Are there differences in logical reasoning and linguistic abilities?
}

\author{
Ehindero, O. J., Adeleke, M.A., Oloyede, E. O. \& Ajibade, Y.A. ${ }^{7}$
}

\begin{abstract}
This study was carried out to further search for the true position of boys and girls in terms of participation and performance in science in classroom settings that are different from the conventional or traditional arrangement. The paper examined the differences in the logical reasoning, linguistic, reading as well as word-problem solving abilities of male and female science students which are considered important to effective learning of science. Forty science students consisting of 20 each of male and female groups were involved in the study. Each group was taught by four science teachers of the same sex for a period of six weeks. The teachers had uniform qualifications. In addition to the subject matter taught processes of science were emphasized throughout the lessons. The study showed that girls have higher achievement scores than boys in logical reasoning, linguistic, reading and word-problem solving abilities. The differences in the scores were also found to be significant at 0.05 confidence level. It was therefore concluded that the issue of gender influence on students' performance in science is not straight jacketed. Boys perform better than girls only in conventional classroom arrangements and in the overall science tasks but not in some tasks that are also very crucial to the learning of science.
\end{abstract}

Keywords: gender differences in science achievement, logical reasoning, linguistic ability, reading ability word-problem solving ability

\section{Introduction}

Within the last twenty years the gender issue in science, technology, mathematics and engineering education has received considerable attention. In particular, the issue of gender inequality in science, technology and engineering featured prominently in the six biennial international Gender and Science and Technology (GASAT) conference (Rennie, Parker and Hildebrand 1991). Ever since then this has continued to receive attention. In Nigeria, as far back as the 1980s among the gender issues that have been receiving considerable attention are under representation of females in science, technology and engineering-related professions (Osibodu,1985 and Balogun, 1985). Negative perception and low performance of females in science subjects in formal educational institutions have also been reported (Folayajo 1984).

\footnotetext{
7 The authors are all lecturers at the Department of Curriculum Studies, Faculty of Education, Obafemi Awolowo University, Ile-Ife, Nigeria. Contact them at ojdero@yahoo.com; ademorf@yahoo.com; eoloyede@oauife.edu.ng \& yettya2000@yahoo.com
} 
Looking at gender disparity in science and mathematics from other angles: Are there differences in logical reasoning and linguistic abilities?

Ehindero, O. J., Adeleke, M.A., Oloyede, E. O. \& Ajibade, Y.A.

Different forms of explanations (biological, social, cultural and psychological) have been offered to account for the reported gender differences both in the abilities and actual performance in science, technology and engineering (Balogun,1985 and Seymour, 1995).

From available literature it would appear that the conclusion drawn and recommendations made from results so far obtained from studies on gender inequality have been predicated mainly within a science philosophy defined, practiced and evaluated strictly within a positivist epistemology. In this context we must assume that we are yet to get to the real issues involved in most reported gender differences. The need to explore a different alternative epistemological research paradigm in understanding and interpreting observed gender differences seem compelling.

According to Eisner (1991), the emergence of alternative paradigms provides platforms from which to examine unexamined assumptions, in effect, their presence forces us to present our position to defend it and therefore to understand it better ... One set of conceptual implications of alternative paradigms is a broader view of knowledge, a cultural view of mind, a multiple view of intelligence and a constructivist view of cognition.

Guba (1991) in a critique of the dominant positivist epistemology within which most reported gender differences in performance in science, mathematics and technology have been assessed and interpreted remarked that

constructivists feel that the positivist (and post-positivist) paradigms are badly flawed and must be entirely replaced... The facts that are collected must be independent of the prepositional (theoretical) statements. But philosophers of science now believe that facts are facts only within some theoretical framework. Thus the basis for discovering 'how things really are' is lost. Reality exists only in the context of a mental framework (construct) for thinking about it.

Constructivist epistemology is therefore subjectivist adopting a relativist ontology in which case, realities are multiple, existing in people's minds. Subjectivity, according to Guba (1991) is not only forced on us by the human condition (as the Post-positivist might admit) but because it is the only means of unlocking the constructions held by individuals. If realities exist only in respondents' minds, subjective interaction seems to be the only way to assess them. In this way constructivism adopts a methodology which intends neither to predict and control the 'real' world nor to transform it but to reconstruct the 'world' at the only point at which it exists- in the minds of constructors. It is the mind that is to be transformed not the 'real' world.

The aim of constructivist science in the context of the on-going debate on gender equity is to create awareness that knowledge in a sense is subjective and that what is needed is to provide opportunities to unlock individuals' potentials to acquire knowledge. The results of some of the studies in Nigeria by Ehindero (Ehindero 1982a, 1982b, 1987, 1995) and Adeleke (2007) would seem to indicate how imperative it is to rethink and recontexualize in a most fundamental way possible the gender issue in light of the emerging and challenging constructivist epistemology. In other words performance in science and mathematics and related disciplines should be rooted in and related to the prevailing structure of the society culture and methodology of science and mathematics. Gender equity or otherwise should also be assessed and interpreted within such structures and methodology.

Science concepts, operations and theories taught in schools are complex structures typically entailing several successive steps of construction involving cognitive hierarchies, hypothetico- 
deductive/deductive and proportional reasoning abilities. This is also the case in mathematics. Complex structures of these types are often constructed within short periods of time. Guided by a teacher, the student (learner) typically executes several successive steps of construction within a few minutes. Such constructions are usually within a socio-cultural context and the teacher's successive steps are also mediated by his/her perceptions, beliefs, values as well as the expectations he/she holds about the students (Ehindero 1986).

The kind of motivation, reinforcement and performance must be able to account for or be related to the types of rapid cognitive processes. Construction and learning processes occur under the guidance of a teacher who communicates and 'markets' scientific concepts to the learner by means of propositions and logical connectives embedded in language which in the case of Nigeria is usually a second language-English.

An important fact that has emerged in recent years in research in science and mathematics education is the growing role and function of linguistic abilities in the acquisition, application and transfer of science and mathematics concepts (Yager, 1992; Reynold et al, 1994; Digisi, 1995 and Ajibade \& Adeleke 2005).

In the Alternative Paradigm Dialog, Guba (1991) warns that nothing is more suspicious in the field of evaluation than a report that is presented with the implication that it has the status of 'holy writ'. Researchers in the pure sciences, and in the more laboratory-oriented of the social and human sciences, now have to accept that good science is a blood brother if not a sibling to what transpires in the more open-ended fields of endeavors. When one analyses the results of some of the studies cited above within positivist epistemology, it seems clear that there is a need for a re-assessment of the epistemological context within which the studies were carried out, the assumptions and the interpretations made. This dominant epistemological paradigm has been challenged (Taylor 1994, and Ehindero 1995).

\section{The Present Study}

The present study attempts to investigate the performance of female and male students in a series of science and mathematics-related tasks. The purpose was to attempt to identify possible variables that might explain possible gender differences in the students' performance in science and mathematics within a modified setting. Vygosky (1978) was of the view that

\footnotetext{
learning and teaching are social activities which take place between social actors in socially constructed situations. Thought development is determined by language i.e by the linguistic tools of thought and by the sociao-cultural experience of the child. The child's intellectual growth is contingent on his/her developing expertise in the social means of thought. (pg 88)
}

Specifically, it is postulated, following Vygosky(1978) and Lawson (1984) that linguistic ability do not only influence the acquisition of complex scientific concepts, but are in fact instrumental to the understanding of and solution to such concepts. Because females tend to use language more than males they should be seen to perform better than males on science tasks which require linguistic abilities for their solution (Howie, 2002). Conversely, it was also hypothesized that following the trend in the literature, males would be expected to out perform females on qualitative mathematically related problems (Opala and Onocha, 1988).

Lawson, Karplus and Adi (1978) and Lawson, Lawson and Lawson (1984) emphasize the role of hypothetical deductive reasoning and linguistic abilities in solving proportions problems, 
Looking at gender disparity in science and mathematics from other angles: Are there differences in logical reasoning and linguistic abilities?

Ehindero, O. J., Adeleke, M.A., Oloyede, E. O. \& Ajibade, Y.A.

Lee and Fradd (1996) provided data which drew the attention of science educators to the crucial role of language and literacy in the acquisition of science concepts. Ajibade and Adeleke (2005) also drew the same attention in mathematics. The summary of the conclusions of these authors are that performance differences exist between the genders. When girls are compared to boys, girls tended to use more language in both oral and written communication and they provided more complete summaries, and expressed more personal feelings than boys. The authors then suggested the need for further studies.

\section{Statement of the problem}

It seems misleading to admit that there is a straight forward superiority in science and mathematics performance between males and females as many studies would make us believe. This sweeping impression has tended to contribute to disparity is science participation and performance in males and females. The global society can no longer accept females seeing themselves as non-participant in science and mathematics just because it appears on the surface that males are better than them whereas they too have what can be offered. The need to explore these seemingly hidden areas informed this study.

\section{Purpose of the study}

The specific objectives of this study include finding out the relative position of male and female science students in the possession of linguistic, logical reasoning and reading abilities as well as the performance in word problems in science.

\section{Research hypotheses}

Hypothesis 1 There is no significant difference in the requisite logical reasoning abilities of male and female science students

Hypothesis 2 There is no significant difference in the linguistic abilities of male and female science students

Hypothesis 3 There is no significant difference in the reading abilities of male and female science students

Hypothesis 4 There is no significant difference in the performance of male and female students in science word problems

\section{Method}

This study adopts a unique arrangement different from the conventional classroom setting. Two classes were used for the study. Each class consisted of twenty students with an average age of 14.75 years drawn from urban environments. Class A all girls was taught by four female teachers ( same sex) undergoing their practice teaching exercise, while class B were all boys taught by four male science teachers ( same sex too) who were also undergoing their practice teaching exercise.

The study is further made unique with the assignment of students to classes based on the results of sociometry which required the students to indicate those they wished to work with in their science class. The students were therefore free to choose those to work with, so as presumably, to encourage greater interactions and participation in the classroom. 
Three concepts were taught during the six-week long practice teaching exercise-pendulum, cell and the general Gas laws. The teaching followed the recommended syllabus and procedure of the junior secondary school (JSS). Three laboratory sessions were conducted for each of the three topics. This strategy was designed to facilitate greater interaction and participation of all the students. The processes of science were emphasized throughout. These included hypothesizing, observation, drawing inferences making conclusions and generalizing.

All the eight teachers possessed the Nigerian Certificate in Education ((NCE) in their respective science disciplines and had taught at the Junior Secondary School level for at least three years prior to enrolling for a bachelor's degree in Science Education at the Obafemi Awolowo University, lle-lfe, Nigeria.

\section{Research Instruments}

\section{(i) Logical reasoning test}

Two conventional Piagetian formal reasoning tasks were used to assess the hypotheticodeductive reasoning ability of the subjects. The first is the Pouring water task (Lawson et al 1984) and the Shadows task (Ehindero 1976, Lawson 1978). The two tasks have stood the test of time and established to be valid and reliable.

\section{(ii) Reading ability test}

This is measured by a cloze test (Taylor 1953 quoted in Hughes, 1989) which consists of a passage titled Heat Engine and Gas Laws of approximately 250 words in which every fifth word is systematically deleted and replaced by a blank of uniform length. Students were required to read the passage and fill in the blanks as best as they can. Only the exact words of the original passage are counted as correct. A score of $35 \%$ or greater is defined as adequate reading comprehension (Borumuth, 1969 and Wright, 1982). The passage was from "The Use of English for Technical Students" (Kelly 1970). The preface to the book states that 'it is intended to provide suitable exercise in technical and scientific exposition such that the students are able to use language functionally and to express themselves clearly and lucidly within their disciplines.

(iii) Science and mathematics problem solving ability

There are ten items in this section. The items required from the students are the abilities and skills for (i) proportional analysis of variables from an equation expressing a functional relationship (ii) matching a verbal description of a functional relationship with an equation that formally expresses the relationship, and (iii) writing equations that express direct and indirect relationships between two variables.

(iv) Linguistic ability test

This was measured with the use of the scores of the students in English Language test designed for assessing linguistic skills. The questions assessed students' ability to recognize, generate, hypothesize and predict in addition to assessing vocabulary comprehension and grammar. The test had a test-retest reliability coefficient of 0.72 
Looking at gender disparity in science and mathematics from other angles: Are there differences in logical reasoning and linguistic abilities?

Ehindero, O. J., Adeleke, M.A., Oloyede, E. O. \& Ajibade, Y.A.

\section{Result}

Results of the analyses of the data collected on the students' achievement scores on the logical reasoning, reading ability, science and mathematics word problems and linguistic ability tests are presented in Tables 1. The table also shows the descriptive statistics (i.e. mean and standard deviation). To ascertain whether the observed differences in the means were significant, the data was subjected to further analysis using t-test and the $t$ and $p$ values obtained in the t-test have also been presented in the tables.

Table 1 t-test summary of difference in logical reasoning ability

\begin{tabular}{|c|c|c|c|c|c|c|c|}
\hline Cognitive ability & Group & $\mathbf{n}$ & $\check{\boldsymbol{x}}$ & s.d & df & $\mathbf{t}$ & $\mathbf{p}$ \\
\hline \multirow[t]{2}{*}{ Logical reasoning } & Females & 20 & 63.7 & 4.89 & \multirow{2}{*}{38} & \multirow[b]{2}{*}{6.55} & \multirow{2}{*}{0.00} \\
\hline & Males & 20 & 50.7 & 7.36 & & & \\
\hline \multirow[t]{2}{*}{ Linguistic ability } & Females & 20 & 33.5 & 1.49 & \multirow{2}{*}{38} & \multirow{2}{*}{9.15} & \multirow{2}{*}{0.00} \\
\hline & Males & 20 & 25.0 & 1.76 & & & \\
\hline \multirow{2}{*}{ Reading ability } & Females & 20 & 29.60 & 3.75 & \multirow[t]{2}{*}{38} & \multirow{2}{*}{5.11} & \multirow{2}{*}{0.00} \\
\hline & Males & 20 & 23.25 & 4.10 & & & \\
\hline Science and mathematics & Females & & & & & & \\
\hline problem solving ability & Males & & & & & & \\
\hline
\end{tabular}

Logical reasoning ability of male and female science students (Hypothesis 1)

The descriptive statistics on the students' logical reasoning ability (Table 1) indicates differences in males and females' scores with the latter outperforming the other (i.e. with females obtaining mean score 63.7 and males 50.7). The results in the table shows a significant difference $(p<0.05)$ in the scores of logical reasoning abilities of male and female science students with the females outperforming their male counterparts.

\section{Linguistic abilities of male and female science students (Hypothesis 2)}

The difference observed in the means obtained on the students' linguistic abilities (male 25.0 and female 33.5) was found to be statistically significant. The results show a significant difference in the linguistic ability of science students $(\mathrm{t}=9.15, \mathrm{df}=38, \mathrm{p}<0.05)$ with female students having higher average linguistic score than male students.

\section{Reading abilities of male and female science students (Hypothesis 3)}

Also on this variable, a difference was observed in the means obtained on the students' reading abilities (male 23.25 and female 29.6). This was found to be statistically significant ( $\mathrm{t}=9.15$, $\mathrm{df}=38, \mathrm{p}<0.05)$ with female students having higher average linguistic score than male students.

\section{Science and mathematics problem solving ability (Hypothesis 4)}

Finally, a difference was also observed in the means obtained on the students' science and mathematics problem solving abilities (male 22.65 and female 30.20). This was found to be statistically significant $(\mathrm{t}=6.20, \mathrm{df}=38)$ at $\mathrm{p}<0.05)$ with female students having higher average word problem solving score than male counterparts. 


\section{Discussion}

In the present study such risks were taken in the structure of the design and implementation of the study objectives in which we ensured active participation of females and provide them opportunities to interact through the provision of female science role models in addition to ensuring small class size and the inclusion of equal number of boys and girls in the classes. It was like a 'risk-taking' research design. The above results had indicated that the risk yielded good results since the design provided a framework for increasing and promoting opportunities for greater and equal gender participation and interaction required for better performance in science and related disciplines. This finds corroborate McGinnis and Pearsall (1998) assertion that it is only by taking risks in our methods of teaching science and by systematically reflecting on these efforts will progress be made in gender equity. Hence there is the need to change and incorporate gender sensitive science pedagogy which involves risks taking in innovating new gender inclusive science pedagogy.

The higher performance of girls over boys in reasoning ability linguistic and word problem solving ability seem to confirm that language and other symbolic systems as in logic and grammar logico-connectives are implicated in higher-level thinking as these have been shown by earlier studies to be more elaborate in girls than boys (Shepardson 1994). The study had demonstrated that if science tasks are too mathematically demanding, boys would be favoured, if too linguistically demanding (as in the science word problems in this study) girls would be favoured. Studies have found out that there is high and positive correlation between linguistic and formal reasoning abilities (Chazen and Cox, 1976). Therefore language is important as a mediator of action and thought and that many aspects of cognitive functioning are facilitated by adequate language skills.

\section{Conclusion}

This study concluded that difference between male and female science students is at best relative depending on the context of the investigation and the content being examined. While males may out perform females in conventional science context dominated by mathematics and experimentation, females achieve higher than males in certain skills that are very necessary to the learning of science. The results of this study suggest that more care needs to be taken when interpreting performances of boys and girls in science tasks. We need to identify the structure of the tasks with regards to their linguistic demands. If we are interested in gender equity in science and related disciplines, it will be necessary for test and curriculum developers to ensure equity/balance in the linguistic and mathematical demands of science tasks.

\section{References}

Adeleke M. A. (2007). Gender disparity in mathematical performance revisited: Can training in problem solving bring difference between boys and girls? Essays in Education online journal. 21. Retrieved from http/www.usca.edu/Essays.

Ajibade Y. A. and Adeleke M. A. (2005). The Nigerian language policy and achievement in mathematics among secondary school students. Paper presented $50^{\text {th }}$ Conference of International Council of Teachers World Assembly, University of Pretoria, South Africa. $1-17$

Allington R. \& Strampe, M. (1980). Learning through reading in the content areas. Lexington. 
Looking at gender disparity in science and mathematics from other angles: Are there differences in logical reasoning and linguistic abilities?

Ehindero, O. J., Adeleke, M.A., Oloyede, E. O. \& Ajibade, Y.A.

Balogun T.A. (1994). Gender issues in the teaching of science, technology and mathematics. In S. Y. Erinosho(Ed), Perspectives on Women in Science and Technology in Nigeria . Ibadan: Sam Bookman.

Borumuth J.R. (1969). Factor validity of close tests as measures of reading comprehension ability. Reading Research Quarterly, 4, 358-365.

DiGisi, L.L. and Willett J.B. (1995) What high school biology teachers say about their textbook use. A Descriptive Study. Journal of Research in Science Teaching, 32 (2) 123-142.

Ehindero, O.J. (1982a) A Developmental Analysis of Certain Piagetian Concepts Among some Nigerian Children. Journal of Research in Science Teaching. 19(1)45-52.

Ehindero, O.J. (1982b) Correlates of sex-related differences in logical reasoning. Journal of Research in Science Teaching 19(7) 53-558.

Ehindero, O.J. (1986) Correlates of physics achievement: The role of gender and non-Induced students lexpectation. The Journal of Experimental Education 54(4) 189-192

Ehindero, O.J.(1995) .Radical Construction as an alternative epistemology and emerging research paradigm in preprimary science education. Paper Prepared to the Second National Conference on Pre-primar Schooling, Adeyemi College of Education, Ondo. November27-Decembe1, 1995

Eisner, E. (1991). The enlightened eye: qualitative inquiry and the enhancement of educational practice, New York: Macmillan Publishing Company

Howie, S. J. (2002). English language proficiency and contextual factors influencing mathematics achievement of secondary school pupils in south africa. Doctoral Dissertation, University of Twente

Hughes, A. (1989). Testing for language teachers: Cambridge University Press

Lawson, A. E., Lawson D. I. and Lawson C.A.(1984) Proportional reasoning and the linguistic abilities required for hypothetic deductive reasoning, JRST,21 (2) 119-131.

Lawson, A.E., Karplus, R. \& Adi H.(1978). The Acquisition of prepositional logic and formal operational schematic during the secondary school years, JRST 15,465-478.

Lee, O. and Fradd, S. H.(1996a). Literacy skills in science performance among culturally and linguistically diverse students. Science Education, 80, 651-671

McGinnis J.R. and Pearsall, M. (1998) Teaching elementary science methods to women: a male professor's experience from two perspectives JRST ,35, 919-949.

Mills, C.J.; Abland K.E. \& Stumpf, H. (1993) Gender differences in academically talented young students' mathematical reasoning: patterns across age and sub-skills. Journal of Educational Psychology ,85, 340-346.

O'Laughlin, M. (1992). Engaging teachers in emencipatory knowledge construction. Journal of Teacher Education, 43(5), 336-346

Opala, P. and Onocha, C. (1988). Students factors as correlate of achievement in physics, Physics Education, 23, 361-364

Osibodu, B.M. (1985) Technology Education and Girls' Participation in Nidgeria. In Girls, Science and Technology. Contribution to GASAT Conference 2, 10-19.

Rennie L. J., Parker L.H, \& Hilderbrand G.M (Eds) (1991) Action for equity: the second decade. perth national key centre for school science and mathematics 
Reynolds, J. and Werner S.C. (1994). An alternative paradigm for college reading and study skills courses. Journal of Reading, 37, 272-279.

Robinson, J.T. (1968). The nature of science and science teaching. California:Wadsworth Publishing Company, Inc.

Seymour, E., (1995). The loss of women from science, mathematics, and engineering undergraduate majors: An explanatory account, Science Education 79, 437

Shepardson, D. P. (1993). Publisher-based science activities of the 1980s and thinking skills. School Science and Mathematics 53(5): 64-268.

Taylor, P.C. (1994). Establishing a critical discourse on cultural myths that shape the social reality of the science classroom. Paper Presented at the National Association for Research in Science Teaching. Anaheim, C.A. 1994.

Taylor, P.C. (1995). College teaching of science and mathematics in Florida: A preliminary foray into the field. Department of Science Education, Florida State University.

Vygosky, L. S. (1978). Thought and language, Cambridge, MA: MIT Press

Willis, J. (1996.) A Framework for task-based learning. London: Longman

Wright J.D.(1982) The Effect of Reduced Readability Text Materials on Comprehension and Biology Achievement. Science Education 66(1), 3-13.

Yager, R.E. (1992) View Point: What we did not learn from the 60's about Science Curriculum Reform. Journal of Research in Science Teaching 29, 905-910. 